\title{
Determination of Total Selenium in Food Samples by d-CPE and HG-AFS
}

\author{
Mei Wang ${ }^{a}$, Yizhou Zhong ${ }^{a}$, Jinpeng Qin ${ }^{b}$, Zehua Zhang ${ }^{a}$, Shan Li ${ }^{a}$, Bingyi YANG ${ }^{a^{*}}$ \\ ${ }^{a}$ School of Public Health, Guangdong Pharmaceutical University, Guangzhou, Guangdong 510310, China \\ ${ }^{b}$ Shandong Jining No.1 People's Hospital, Jining, Shandong 272011, China
}

Abstract A dual-cloud point extraction（d-CPE） procedure was developed for the simultaneous preconcentration and determination of trace level Se in food samples by hydride generation-atomic fluorescence spectrometry (HG-AFS). The Se(IV) was complexed with ammonium pyrrolidinedithiocarbamate (APDC) in a Triton X-114 surfactant-rich phase, which was then treated with a mixture of $16 \%(v / v) \mathrm{HCl}$ and $20 \%(v / v) \mathrm{H}_{2} \mathrm{O}_{2}$. This converted the Se(IV)-APDC into free Se(IV), which was back extracted into an aqueous phase at the second cloud point extraction stage. This aqueous phase was analyzed directly by HG-AFS. Optimization of the experimental conditions gave a limit of detection of $0.023 \mu \mathrm{g} \mathrm{L}{ }^{-1}$ with an enhancement factor of 11.8 when $50 \mathrm{~mL}$ of sample solution was preconcentrated to $3 \mathrm{~mL}$. The relative standard deviation was $4.04 \%$ ( $c=6.0 \mu \mathrm{g} \mathrm{L}{ }^{-1}, n=10$ ). The proposed method was applied to determine the Se contents in twelve food samples with satisfactory recoveries of $95.6-105.2 \%$.

Keywords Dual-cloud point extraction; Hydride generation-atomic fluorescence spectrometry; Selenium; Box-Behnken design; Response surface methodology

\section{Introduction}

Selenium (Se) is an essential trace element with multiple biological functions in many organisms, including humans. It is found in at least 25 human selenoproteins in the form of selenocysteine, a rare amino acid implicated in redox reactions when present at the active site of enzymes, such as glutathione peroxidases and thioredoxin reductases (Legrain, Touat-Hamici, \& Chavatte, 2014; Pedrero \& Madrid, 2009). However, the concentration range at which Se is 
beneficial to human health is narrow (50-200 $\mu \mathrm{g} \mathrm{day}^{-1}$ ) (Pyrzyn’ska, 2001).

Supplemental Se may be acquired through food, but the bioavailability and toxicity of Se depends on its concentration and chemical form in food (Fairweather-Tait, 1997; Finley, 2006). Because of the small difference between required and toxic levels, reliable and sensitive quantification methods for Se in food are very important. Although the sensitivities of modern analytical techniques are constantly increasing, preconcentration and separation technologies are required because of the low concentration of Se and complexity of the matrix.

Cloud point extraction (CPE) using a nonionic surfactant has become an alternative to conventional solvent extraction in analytical chemistry because it is simple, inexpensive, has high preconcentration factors, and the solvents are less toxic to the environment (Pytlakowska, Kozik, \& Dabioch, 2013). This technique is based on the ability of nonionic surfactants to form micelles in an aqueous solution heated to a temperature known as cloud point temperature (CPT). Above the CPT, the micellar solution separates into two phases: a small volume surfactant-rich phase that contains the analyte, and an aqueous phase containing a low concentration of surfactant. To date, CPE has been widely applied to the extraction of trace metal ions from various matrices through the formation and pre-concentration of chelates (Labrecque, Whitty-Leveille, \& Lariviere, 2013; Silva, Roldan Pdos, \& Gine, 2009; Ulusoy, Akcay, Ulusoy, \& Gurkan, 2011). There are several reports of $\mathrm{CPE}$ as a pre-concentration step for the determination of Se by different spectrometric techniques, including spectrophotometry (Soruraddin, Heydari, Puladvand, \& Zahedi, 2011; Wen, Zhang, Li, Fang, \& Zhang, 2014), spectrofluorimetry (Güler, Maden, Bakırdere, Yavuz Ataman, \& Volkan, 2011), graphite furnace atomic absorption spectrometry(GF-AAS)(Sun, Liu, \& Wu, 2013), electrothermal atomic absorption(ET-AAS)(Ghambarian, Yamini, Saleh, Shariati, \& Yazdanfar, 
2009; Li, Hu, He, \& Xiang, 2008; Sounderajan, Kumar, \& Udas, 2010) and electrothermal vaporization inductively coupled plasma mass spectrometry(ETV-ICPMS)(Chen, $\mathrm{Hu}, \& \mathrm{He}, 2006$; Li et al., 2008). However, CPE coupled with hydride generation atomic fluorescence spectrometry (HG-AFS) has yet to be investigated. HG-AFS is a sensitive analytical method for the determination of trace levels of Se (Lopes Dos Santos et al., 2014; Q. X. Zhao, Chen, Belzile, \& Wang, 2010). The surfactant-rich phase obtained from CPE cannot be analyzed directly by HG-AFS because it is highly likely that the surfactant would produce large quantities of foam during hydride generation, which would destabilize the signal and could overflow from the system into the atomizer. Moreover, complexed Se cannot completely react with hydrogen to form $\mathrm{H}_{2} \mathrm{Se}$ in the hydride generation system, although the influence of surfactants can be overcome to a great extent through the addition of antifoaming agents.

Fortunately, with a dual-cloud point extraction(d-CPE) technique, the above drawbacks of traditional CPE can be circumvented. Yin (2007) first proposed d-CPE for capillary electrophoresis speciation analysis of mercury. In d-CPE, the CPE procedure is performed twice during a single sample pretreatment process, followed by back extraction of the analyte into an aqueous phase at the second CPE step. Zhao L., Zhong, Fang, Qian, \& Chen (2012) reported a d-CPE procedure for the determination of several metals $\left(\mathrm{Cd}^{2+}, \mathrm{Co}^{2+}, \mathrm{Ni}^{2+}, \mathrm{Pb}^{2+}, \mathrm{Zn}^{2+}\right.$ and $\mathrm{Cu}^{2+}$ ions) in water by inductively coupled plasma optic emission spectrometry (ICP -OES). Arain, Kazi, Arain, et al. (2014) used d-CPE for pre-concentration of As, $\mathrm{Cd}$, Ni and $\mathrm{Pb}$ in an artificial saliva extract. Recently, this method has been applied to the extraction and pre-concentration of $\mathrm{Cu}^{2+}$ in serum samples from viral hepatitis patients before quantification by flame atomic absorption spectrometry (Arain, Kazi, Afridi, et al., 2014). Apart from the above-mentioned 
publications, d-CPE has not been used for trace metal detection. Furthermore, in all studies except that involving determination of $\mathrm{Cu}^{2+}$ by flame atomic absorption spectrometry, the experimental parameters of d-CPE have been optimized using a traditional univariate methodology. This optimization method is time consuming because many experiments are required, and possible interactions among variables could be missed. Multivariate techniques are faster, and more economical and effective because they allow for simultaneous optimization of more than one variable. Response surface methodology (RSM) is an effective statistical tool for determining the optimal conditions in a multivariable system with a minimum number of experiments, and its use in the field of analytical chemistry is increasing.

The purpose of this study was to develop a new method using d-CPE in combination with HG-AFS for the determination of trace level $\mathrm{Se}$ in food samples. Ammonium pyrrolidinedithiocarbamate (APDC) was used to form a hydrophobic complex with Se(IV), which was then encapsulated by the nonionic surfactant Triton X-114 and back extracted with a mixture of $16 \%(v / v) \mathrm{HCl}$ and $20 \%(v / v) \mathrm{H}_{2} \mathrm{O}_{2}$. This final step could minimize the adverse effects of the surfactant and convert Se-APDC complexes into Se(IV) before its reduction to $\mathrm{SeH}_{2}$ by $\mathrm{KBH}_{4}$ for subsequent HG-AFS detection. The experimental variables (APDC and Triton X-114 concentrations, $\mathrm{pH}$ and equilibration temperature) for the d-CPE were optimized using a Box-Behnken design with three variables.

\section{Materials and Methods}

\subsection{Apparatus}

A model AFS-920 double-channel non-dispersive atomic fluorescence spectrometer (Beijing Jitan Instruments Co. Ltd., Beijing, China) was employed for all experiments. A selenium hollow 
cathode lamp (Beijing Institute of Vacuum Electronics, Beijing, China) was used as the radiation source. The instrumental parameters were adjusted according to the manufacturer's recommendations, which are shown in Table 1. A DK-600 thermostated bath (Shanghai Precision Experimental Equipment Co. Ltd., Shanghai, China) was used to maintain the desired temperature. A centrifuge (Anke KA-1000, Shanghai, China) was used to enhance phase separation. The $\mathrm{pH}$ values were measured with a model PHS-3C pH-meter (Shanghai Hongyi Instrument Instrument Co., Ltd., Shanghai, China).

\subsection{Chemicals and reagents}

All chemicals and reagents used in this work were of analytical grade or higher purity. Ultrapure water was purified with a SZ-97 automatic triple water distiller (Shanghai Yarong Biochemical Instrument Factory, Shanghai, China). Working solutions of Se(IV) were prepared by serial dilution with ultrapure water from $1000 \mathrm{mg} \mathrm{L}^{-1}$ stock solutions (Beijing Nuclear Industry Institute of Chemical Metallurgy, Beijing, China). A $1 \mathrm{~g} \mathrm{~L}^{-1}$ APDC (Shanghai Richjoint Chemical Reagent Co., Ltd., Shanghai, China) solution was prepared in ultrapure water. The nonionic surfactant, Triton X-114, was obtained from Sigma-Aldrich (St. Louis, MO) and used without further purification. A buffer solution was used. A mixture of $16 \%(v / v) \mathrm{HCl}$ and $20 \%(v / v) \mathrm{H}_{2} \mathrm{O}_{2}$ (Guangzhou Chemical Reagent Factory, Guangzhou, China) was used for back extractions. All vessels and pipettes used for Se(IV) analysis were treated with $10 \% \mathrm{HNO}_{3}$ for at least $24 \mathrm{~h}$ and washed four times with ultrapure water.

\section{$2.3 d$-CPE procedure}

The d-CPE procedure was based on a conventional CPE process. An aliquot $(50 \mathrm{~mL})$ of either the sample or $\mathrm{Se}(\mathrm{IV})$ standard with a concentration between 0.5 and $6.0 \mu \mathrm{g} \mathrm{\textrm {L } ^ { - 1 }}$ was mixed 
with 0.8 to $1.2 \mathrm{~mL}$ of $5 \%(\mathrm{~m} / \mathrm{v})$ Triton $\mathrm{X}-114$ and 0.6 to $1.4 \mathrm{~mL}$ of $1 \mathrm{~g} \mathrm{~L}^{-1}$ APDC. The mixture was kept in a thermostatic bath at 40 to $70{ }^{\circ} \mathrm{C}$ for $15 \mathrm{~min}$. The $\mathrm{pH}$ was buffered at 1.0 to 5.0. The turbid solution was centrifuged for $10 \mathrm{~min}$ at $2925 \times \mathrm{g}$, and then cooled in an ice water bath for $10 \mathrm{~min}$ to increase the viscosity of the surfactant-rich phase, which was retained in the bottom layer. The aqueous phase was removed with a pipette. Instead of adding a diluent or proceeding with the analysis, a second CPE was performed. In the second CPE, the surfactant-rich phase, which contained the complexes, was treated with $3 \mathrm{~mL}$ of a solution containing $16 \%(v / v) \mathrm{HCl}$ and $20 \%$ $(v / v) \mathrm{H}_{2} \mathrm{O}_{2}$ and then heated in a thermostatic bath at $40-70{ }^{\circ} \mathrm{C}$ for $15 \mathrm{~min}$. This step was followed by centrifugation for $10 \mathrm{~min}$ at $2925 \times g$. Finally, the supernatant was introduced into the HG-AFS system for analysis. Blank samples were also prepared in a similar way.

\subsection{Sample preparation}

Twelve food samples were purchased in Guangzhou, China. The samples were ground to reduce the particle size, and stored at $4{ }^{\circ} \mathrm{C}$. Each sample $(0.5-1 \mathrm{~g})$ was placed in a glass beaker, and $15 \mathrm{~mL}$ of digestion mixture $\left(\mathrm{HNO}_{3} / \mathrm{HClO}_{4}, 4 / 1, v / v\right)$ was added. The samples were gently heated on a hot plate at $120{ }^{\circ} \mathrm{C}$ to near dryness. After cooling to room temperature, $5 \mathrm{~mL}$ of $6 \mathrm{~mol} \mathrm{~L}^{-1}$ $\mathrm{HCl}$ was added to the mixture and the solution was heated until the volume reduced to approximately $1 \mathrm{~mL}$. This reduced $\mathrm{Se}(\mathrm{VI})$ to $\mathrm{Se}(\mathrm{IV})$. Finally, the residue was transferred to a 50-mL volumetric flask, diluted with ultra-pure water, and extracted using the procedure in Section 2.3.

\subsection{Optimization procedure}

Based on the results of single-factor experiments, four variables that greatly affected the recovery of Se(IV) were optimized using RSM. A four-factor, three-level Box-Behnken design 
with 27 runs was employed. The following four variables were selected: $\mathrm{X}_{1}, \mathrm{pH} ; \mathrm{X}_{2}$, concentration of APDC; $\mathrm{X}_{3}$, concentration of Triton X-114; and $\mathrm{X}_{4}$, equilibration temperature. Each variable was assessed at three different levels (Table 2). Second-order polynomial coefficients were calculated and analyzed using SAS 9.1 (SAS Institute, Cary, NC). Statistical analysis of the regression model and the significance of parameter estimates were determined by analysis of variance (ANOVA).

\section{Results and Discussion}

\subsection{Optimization by RSM}

\subsubsection{Statistical analysis and model fitting}

A Box-Behnken design was used to investigate mutual interactions between significant factors and to determine values for these factors that would maximize the extraction efficiency. The design matrix and the experimental data are shown in Table 3. Multiple regression analysis was used to analyze the data, and a quadratic model for the $\mathrm{Se}(\mathrm{IV})$ fluorescence intensity $(F)$ was developed:

$$
F=5689+829 \mathrm{X}_{1}+685 \mathrm{X}_{2}+337 \mathrm{X}_{3}-228 \mathrm{X}_{4}-923 \mathrm{X}_{1}^{2}+295 \mathrm{X}_{1} \mathrm{X}_{3}-1198 \mathrm{X}_{2}^{2}-953 \mathrm{X}_{3}^{2}-
$$

$300 \mathrm{X}_{3} \mathrm{X}_{4}-715 \mathrm{X}_{4}^{2}$,

where $\mathrm{X}_{1}, \mathrm{X}_{2}, \mathrm{X}_{3}$, and $\mathrm{X}_{4}$ represent the $\mathrm{pH}, \mathrm{APDC}$ concentration, Triton $\mathrm{X}-114$ concentration, and equilibration temperature, respectively. The adequacy of the regression model was evaluated using ANOVA. The model $F$-value $(40.28)$ and very low $p$-value $(<0.0001)$ suggested that the model was highly significant, while the lack of fit was not significant $(p=0.1002>0.05)$. The results of the analysis also suggested that the obtained experimental data were in good agreement with the model. The coefficient of determination $\left(R^{2}\right)$ of the model was 0.9792 , indicating that the model explained $97.92 \%$ of the total variation with a residual of $2.08 \%$ unexplained by the model. 
Meanwhile, the low value of the coefficient of variation (5.48\%) demonstrated that the experiment was highly precise and reliable. According to the results of ANOVA, the linear terms $\mathrm{X}_{1}, \mathrm{X}_{2}, \mathrm{X}_{3}$ and $\mathrm{X}_{4}$, and the quadratic terms $\mathrm{X}_{1}^{2}, \mathrm{X}_{2}^{2}, \mathrm{X}_{3}^{2}$ and $\mathrm{X}_{4}^{2}$ significantly affected the $\mathrm{Se}(\mathrm{IV})$ fluorescence intensity $(p<0.05)$. The interaction terms of $\mathrm{X}_{1} \mathrm{X}_{3}$ and $\mathrm{X}_{3} \mathrm{X}_{4}(p<0.05)$ were also significant for the fluorescence intensity. The other interaction terms were not significant $(p>0.05)$.

\subsubsection{Analysis of response surface}

Three-dimensional response surface plots (Fig. 1) and two-dimensional counter plots(Fig. 2) were obtained using SAS 9.1. Each figure displays the effect of two independent variables while keeping the other variables at the center point. Visible peaks in the response surface plots signify that the optimum condition was inside the design range well. All four variables $(\mathrm{pH}$, concentrations of APDC and Triton X-114, and equilibration temperature) affected the fluorescence intensity (Fig. 1). This finding was in agreement with the results of ANOVA. As shown in the response surface plots, the fluorescence intensity increased as two variables approached their optimum conditions, and then decreased as the variables moved away from their optimized values. However, among the interaction terms, only those between the Triton X-114 concentration $\left(\mathrm{X}_{3}\right)$ and the other two factors $\left(\mathrm{pH}, \mathrm{X}_{1}\right.$ and equilibration temperature, $\left.\mathrm{X}_{4}\right)$ were significant The fluorescence intensity rapidly increased with increases in $\mathrm{pH}$, Triton $\mathrm{X}-114$ concentration, and equilibration temperature (Fig. 1b and 1f). There were clear maxima when the Triton $\mathrm{X}-114$ concentration was zero, the $\mathrm{pH}$ was high, and the equilibration temperature was low. These results indicated that $\mathrm{pH}$ influenced formation of the hydrophobic complex, and that higher equilibration temperatures led to decomposition of the hydrophobic complex. Meanwhile, the elliptical nature of contour plots (Fig. 2b and Fig. 2f) suggested that there were considerable 
interactions among them.

According to canonical analysis, the optimum extraction conditions were as follows: $\mathrm{pH} 4.0$, $2.25 \times 10^{-2} \mathrm{~g} / \mathrm{L}$ APDC, $0.11 \%(\mathrm{~m} / \mathrm{v})$ Triton $\mathrm{X}-114$ and an equilibration temperature of $51.4{ }^{\circ} \mathrm{C}$. Under these conditions the predicted value for the fluorescence intensity was 6091, which agreed with the mean experimental fluorescence intensity of 6087 . Therefore, the developed model was accurate and reliable in predicting the fluorescence intensity of extracted $\mathrm{Se}(\mathrm{IV})$.

\subsection{Effect of the concentration of the back extraction agent}

For the second CPE, the choice of back extraction agent is essential to successful coupling of d-CPE preconcentration to HG-AFS. The hydrophobic complex of Se(IV)-APDC should be converted to water-soluble Se(IV) before its back extraction into an aqueous phase. Dilute $\mathrm{HCl}$ was considered a favorable medium for hydride generation and was examined for its suitability as the back extraction agent. The $\mathrm{HCl}$ concentration was optimized in the $5 \%-25 \%(v / v)$ range, and $16 \% \mathrm{HCl}$ was the optimal volume fraction. However, the experimental fluorescence intensity of $\mathrm{Se}(\mathrm{IV})$ was weak, suggesting that the efficiency of back extraction with this $\mathrm{HCl}$ concentration was rather low.

To improve the efficiency of back extraction, $\mathrm{H}_{2} \mathrm{O}_{2}$, a convenient and effective oxidizing agent, was included in the $16 \%(v / v) \mathrm{HCl}$ solution, which allowed for rapid and complete oxidative digestion of the $\mathrm{Se}(\mathrm{IV})$-APDC complex. $\mathrm{H}_{2} \mathrm{O}_{2}$ can oxidize the sulfhydryl group to $-\mathrm{SOH},-\mathrm{SO}_{2} \mathrm{H}$, or $-\mathrm{SO}_{3} \mathrm{H}$ (Howard, M., Jurbergs, H. A., \& Holcombe, J. A., 1998). APDC contains a sulfhydryl group, and addition of $\mathrm{H}_{2} \mathrm{O}_{2}$ to $\mathrm{Se}(\mathrm{IV})$-APDC resulted in release of free $\mathrm{Se}(\mathrm{IV})$. The fluorescence intensity increased sharply when the $\mathrm{H}_{2} \mathrm{O}_{2}$ volume fraction was increased from $5 \%$ to $15 \%$, and leveled off in the volume fraction range $15 \%-25 \%$. Therefore, a solution containing $16 \%(\mathrm{v} / \mathrm{v})$ 
$\mathrm{HCl}$ and $20 \%(v / v) \mathrm{H}_{2} \mathrm{O}_{2}$ was employed to extract $\mathrm{Se}(\mathrm{IV})$ ions from the hydrophobic complexes for extraction back into an aqueous phase.

\subsection{Interference}

The selectivity of the proposed d-CPE towards Se(IV) was examined by investigating the effects of foreign ions on the determination of $6.0 \mu \mathrm{g} \mathrm{L}^{-1} \mathrm{Se}(\mathrm{IV})$. The influence of each ion was considered significant when its presence altered the recovery of Se(IV) by more than $\pm 5 \%$. The tolerable mass ratios of foreign ions to Se(IV) were found to be greater than 5000 for $\mathrm{K}^{+}$and $\mathrm{Na}^{+}$, 2000 for $\mathrm{Mg}^{2+}$ and $\mathrm{Ca}^{2+}, 1000$ for $\mathrm{Al}^{3+}, 400$ for $\mathrm{Fe}^{3+}, 100$ for $\mathrm{Pb}^{2+}, 20$ for $\mathrm{Cd}^{2+}$, and $5 \mathrm{for}^{2+}$. Most of the foreign ions investigated had no considerable influence on the determination of Se(IV) because of the selectivity of APDC at the working $\mathrm{pH}$. However, the tolerable mass ratios of $\mathrm{Cd}^{2+}$ and $\mathrm{Cu}^{2+}$ were much lower, probably because they could react with APDC in competition with $\mathrm{Se}(\mathrm{IV})$. Therefore, a high concentration of APDC was used to ensure complete chelation of $\mathrm{Se}(\mathrm{IV})$.

\subsection{Analytical figures of merit}

The calibration curve of Se(IV) was obtained by preconcentration of a $50-\mathrm{mL}$ sample under the optimized conditions. Solutions of Se(IV) with concentrations between 0.5 and $6.0 \mu \mathrm{g} \mathrm{L}^{-1}$ were analyzed by conventional CPE for comparison with the d-CPE method. Table 5 lists the calibration parameters, relative standard deviations for 10 replicate determinations at the $6.0 \mu \mathrm{g}$ $\mathrm{L}^{-1}$ level, and limits of detection (LOD). The calibration parameters, RSD, and LOD obtained by d-CPE were much better than those obtained by conventional CPE.

Although an antifoam solution can be added to quench surfactant foaming during hydride generation, the fluorescence signal obtained using conventional CPE was weak and the regression 
coefficient $\left(r^{2}\right)$ was only 0.9625 . This could occur if the Se(IV) is not completely released from the Se(IV)-APDC complex, leading to low efficiency of hydride generation. In d-CPE, a mixture of $16 \%(v / v) \mathrm{HCl}$ and $20 \%(v / v) \mathrm{H}_{2} \mathrm{O}_{2}$ converted the $\mathrm{Se}(\mathrm{IV})$-APDC into free $\mathrm{Se}(\mathrm{IV})$, which was rapidly and completely reduced to $\mathrm{H}_{2} \mathrm{Se}$ and directly determined by HG-AFS. The developed d-CPE had better sensitivity and precision with a wider dynamic linear range than CPE.

Finally, the newly developed d-CPE method was compared with other published methods for the extraction and determination of $\mathrm{Se}(\mathrm{IV})$ (Table 6). Despite the relatively low enhancement factor, which was attributed to a large extract volume $(3 \mathrm{~mL})$, the LOD of the proposed method was comparable to reported methods. Compared with solvent extraction, the instrumentation for CPE is simple and inexpensive, and the method does not use toxic organic solvents. The hydrophobic species, which is extracted into the surfactant-rich phase, is separated from the complicated sample matrix with a high-enrichment factor because of the small volume of surfactant-rich phase. CPE is a well-established method for separation and preconcentration of hydrophobic species. In addition to the above advantages of traditional CPE, d-CPE eliminates the effect of surfactant foaming and has a wide application range for sample pretreatment.

\subsection{Analysis of food samples}

The developed procedure was applied to the determination of $\mathrm{Se}(\mathrm{IV})$ in different food samples. Recovery experiments were also carried out by spiking food samples with different amounts of the Se(IV) standard before pretreatment. Reasonable recoveries (95.6-105.2\%) were obtained (Table 7). To further validate the reliability of the proposed method, the certified reference materials GBW 10045 (rice), GBW 10023 (laver), and GBW 10025 (spirulina) were 
analyzed. The total selenium concentrations were $0.038 \pm 0.010,0.119 \pm 0.012$, and $0.228 \pm 0.06$ $\mu \mathrm{g} \mathrm{L}^{-1}(n=6)$ for rice, laver and spirulina respectively. These results were in good agreement with the certified values of $0.04 \pm 0.013$ (rice), $0.124 \pm 0.014$ (laver), and $0.24 \pm 0.05 \mu \mathrm{g} \mathrm{L}^{-1}$ (spirulina). These results showed that there was no matrix interference.

\section{Conclusions}

A novel d-CPE method was developed for the preconcentration and determination of trace Se(IV) by HG-AFS. Compared with traditional CPE, the developed d-CPE technique eliminated deleterious effects of the surfactant during hydride generation and converted the Se(IV) complex into Se(IV) to enhance the fluorescence signal. The extract obtained by d-CPE could be measured directly by HG-AFS. Additionally, RSM was useful for optimization of the experimental factors, and was used to evaluate interactions between multiple variables. The proposed method was successfully applied to the determination of selenium content in twelve food samples.

The LOD of the proposed method was similar to the values reported for more complex and expensive instrumentation, despite a relatively low enrichment factor. Further improvement in the detection limit and enrichment factor could be achieved by reducing the extract volume.

\section{Acknowledgments}

This work was supported by the National Science Foundation of China (grant number NSFC 81202251), the Science and Technology Program of Guangzhou, China (grant number 2014J4100085), and the Science and Technology Infrastructure Development Program of Guangdong, China (grant numbers 2013B060100004 and 2014A040401085). We thank associate professor $\mathrm{Xu}$ Ying for assisting us with the experimental design.

\section{References}


Arain, S. A., Kazi, T. G., Afridi, H. I., Abbasi, A. R., Panhwar, A. H., Naeemullah, . . Arain, M. B. (2014). Application of dual-cloud point extraction for the trace levels of copper in serum of different viral hepatitis patients by flame atomic absorption spectrometry: a multivariate study. Spectrochim Acta A Mol Biomol Spectrosc, 133, 651-656.

Arain, S. A., Kazi, T. G., Arain, J. B., Afridi, H. I., Brahman, K. D., \& Naeemullah. (2014). Preconcentration of toxic elements in artificial saliva extract of different smokeless tobacco products by dual-cloud point extraction. Microchemical Journal, 112, 42-49.

Chen, B., Hu, B., \& He, M. (2006). Cloud point extraction combined with electrothermal vaporization inductively coupled plasma mass spectrometry for the speciation of inorganic selenium in environmental water samples. Rapid Commun Mass Spectrom, 20(19), 2894-2900.

Fairweather-Tait, S. J. (1997). Bioavailability of selenium. European Journal of Clinical Nutrition, 51, s20-s23.

Finley, J. W. (2006). Bioavailability of Selenium from Foods. Nutrition Reviews, 64(3), 146-151.

Güler, N., Maden, M., Bakırdere, S., Yavuz Ataman, O., \& Volkan, M. (2011). Speciation of selenium in vitamin tablets using spectrofluorometry following cloud point extraction. Food Chemistry, 129(4), 1793-1799.

Ghambarian, M., Yamini, Y., Saleh, A., Shariati, S., \& Yazdanfar, N. (2009). Taguchi OA16 orthogonal array design for the optimization of cloud point extraction for selenium determination in environmental and biological samples by tungsten-modified tube electrothermal atomic absorption spectrometry. Talanta, 78(3), 970-976.

Howard, M., Jurbergs, H. A., \& Holcombe, J. A. (1998). Effects of oxidation of immobilized poly (L-cysteine) on trace metal chelation and preconcentration. Anal Chem, 70(8), 1604-1609. 
Labrecque, C., Whitty-Leveille, L., \& Lariviere, D. (2013). Cloud point extraction of plutonium in environmental matrixes coupled to ICPMS and alpha spectrometry in highly acidic conditions. Anal Chem, 85(21), 10549-10555.

Legrain, Y., Touat-Hamici, Z., \& Chavatte, L. (2014). Interplay between selenium levels, selenoprotein expression, and replicative senescence in WI-38 human fibroblasts. J Biol Chem, 289(9), 6299-6310.

Li, Y., Hu, B., He, M., \& Xiang, G. (2008). Simultaneous speciation of inorganic selenium and antimony in water samples by electrothermal vaporization inductively coupled plasma mass spectrometry following selective cloud point extraction. Water Res, 42(4-5), 1195-1203.

Lopes Dos Santos, W. N., Macedo, S. M., Teixeira da Rocha, S. N., Souza de Jesus, C. N., Cavalcante, D. D., \& Hatje, V. (2014). Evaluation of optimal conditions for determination of low selenium content in shellfish samples collected at Todos os Santos Bay, Bahia, Brazil using HG-AFS. Environ Monit Assess, 186(8), 5027-5032.

Pedrero, Z., \& Madrid, Y. (2009). Novel approaches for selenium speciation in foodstuffs and biological specimens: a review. Anal Chim Acta, 634(2), 135-152.

Pyrzyn’ska, P. (2001). Analysis of selenium species by capillary electrophoresis.. Talanta, 55, 657-667.

Pytlakowska, K., Kozik, V., \& Dabioch, M. (2013). Complex-forming organic ligands in cloud-point extraction of metal ions: a review. Talanta, 110, 202-228.

Silva, E. L., Roldan Pdos, S., \& Gine, M. F. (2009). Simultaneous preconcentration of copper, zinc, cadmium, and nickel in water samples by cloud point extraction using 4-(2-pyridylazo)-resorcinol and their determination by inductively coupled plasma optic emission spectrometry. J Hazard Mater, 171(1-3), 1133-1138. 
Soruraddin, M. H., Heydari, R., Puladvand, M., \& Zahedi, M. M. (2011). A new spectrophotometric method for determination of selenium in cosmetic and pharmaceutical preparations after preconcentration with cloud point extraction. Int J Anal Chem, 2011, 729651.

Sounderajan, S., Kumar, G. K., \& Udas, A. C. (2010). Cloud point extraction and electrothermal atomic absorption spectrometry of Se (IV)--3,3'-diaminobenzidine for the estimation of trace amounts of Se (IV) and Se (VI) in environmental water samples and total selenium in animal blood and fish tissue samples. J Hazard Mater, 175(1-3), 666-672.

Sun, M., Liu, G., \& Wu, Q. (2013). Speciation of organic and inorganic selenium in selenium-enriched rice by graphite furnace atomic absorption spectrometry after cloud point extraction. Food Chem, 141(1), 66-71.

Ulusoy, H. I., Akcay, M., Ulusoy, S., \& Gurkan, R. (2011). Determination of ultra trace arsenic species in water samples by hydride generation atomic absorption spectrometry after cloud point extraction. Anal Chim Acta, 703(2), 137-144.

Wang, Y., Xie, J., Wu, Y., Hu, X., Yang, C., \& Xu, Q. (2013). Determination of trace amounts of Se(IV) by hydride generation atomic fluorescence spectrometry after solid-phase extraction using magnetic multi-walled carbon nanotubes. Talanta, 112, 123-128.

Wen, X., Zhang, Y., Li, C., Fang, X., \& Zhang, X. (2014). Comparison of rapidly synergistic cloud point extraction and ultrasound-assisted cloud point extraction for trace selenium coupled with spectrophotometric determination. Spectrochim Acta A Mol Biomol Spectrosc, 123, 200-205.

Yin, X. B. (2007). Dual-cloud point extraction as a preconcentration and clean-up technique for capillary electrophoresis speciation analysis of mercury. J Chromatogr A, 1154(1-2), 437-443.

Zhao, L., Zhong, S., Fang, K., Qian, Z., \& Chen, J. (2012). Determination of cadmium(II), cobalt(II), 
nickel(II), lead(II), zinc(II), and copper(II) in water samples using dual-cloud point extraction and inductively coupled plasma emission spectrometry. J Hazard Mater, 239-240, 206-212.

Zhao, Q. X., Chen, Y. W., Belzile, N., \& Wang, M. (2010). Low volume microwave digestion and direct determination of selenium in biological samples by hydride generation-atomic fluorescence spectrometry. Anal Chim Acta, 665(2), 123-128. 


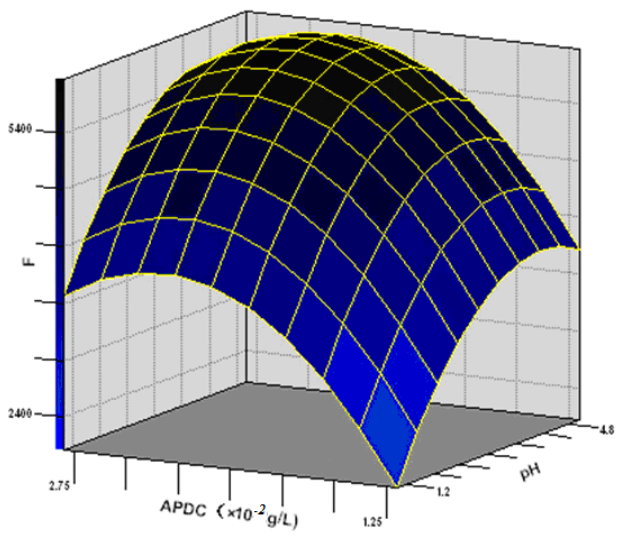

$\mathrm{C}$
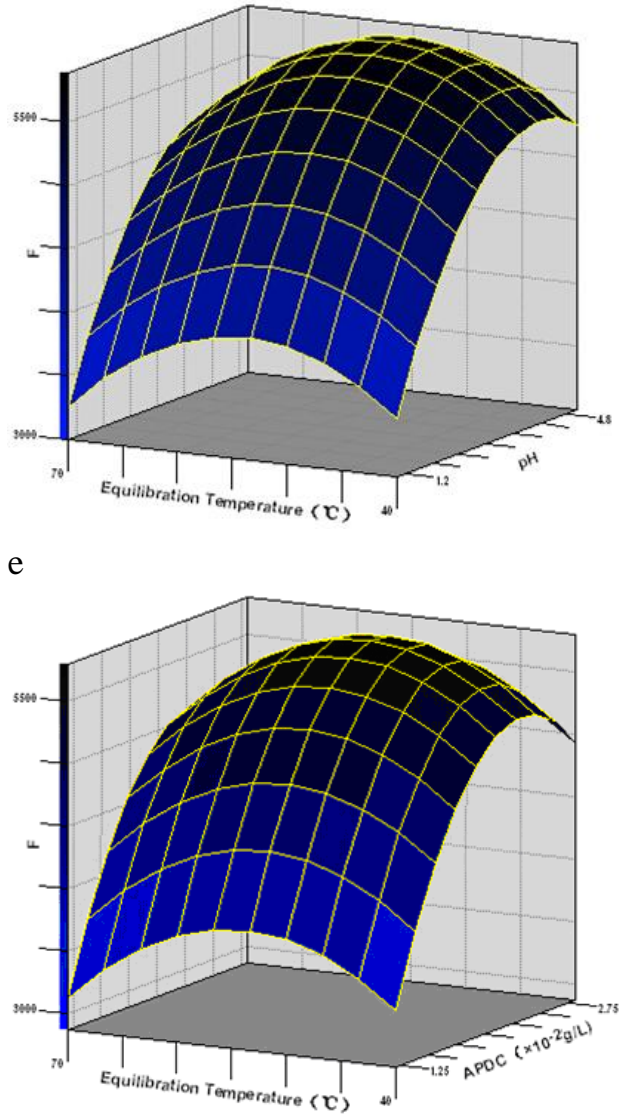

b

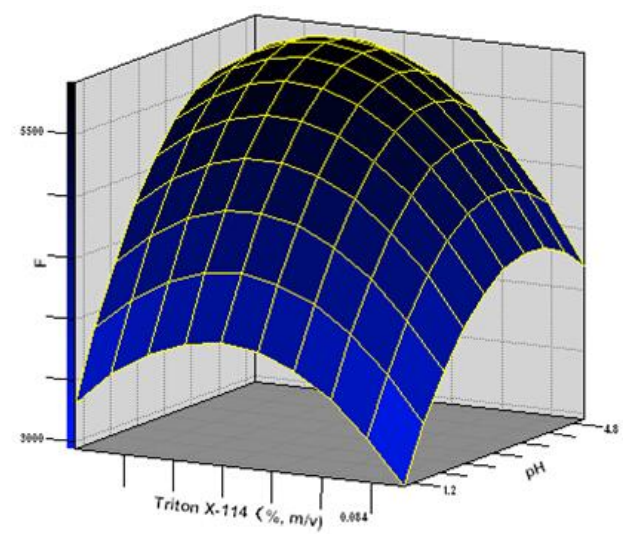

d

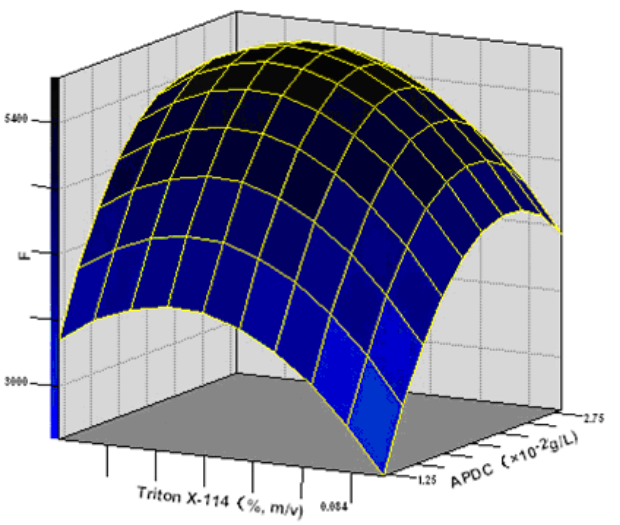

f

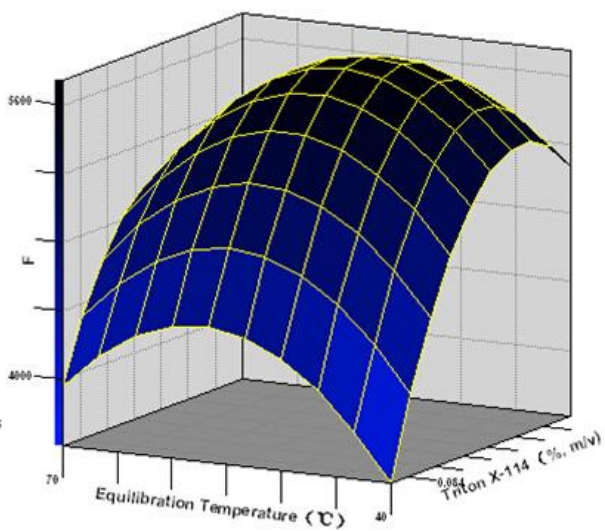

Fig. 1 Response surface for fluorescence intensity of Se(IV) extracted by the d-CPE method 
Table 1 Operating parameters of the HG-AFS instrument

\begin{tabular}{ll}
\hline Parameters & Conditions \\
\hline PTM voltage $(\mathrm{V})$ & 260 \\
Atomizer temperature $\left({ }^{\circ} \mathrm{C}\right)$ & 200 \\
Atomizer height $(\mathrm{mm})$ & 9 \\
Lamp current $(\mathrm{mA})$ & 30 \\
Flow rate of carrier gas $(\mathrm{Ar})\left(\mathrm{mL} \mathrm{min}^{-1}\right)$ & 400 \\
Flow rate of shield gas $(\mathrm{Ar})\left(\mathrm{mL} \mathrm{min}^{-1}\right)$ & 800 \\
Read mode & Peak area \\
Measure method & Std. curve \\
Read time $(\mathrm{s})$ & 10 \\
Delay time(s) & 0.5 \\
Read repeat $($ times $)$ & 1 \\
Injection volume $(\mathrm{mL})$ & 1.0 \\
\hline
\end{tabular}

Table 4 ANOVA results of factors and model in the response surface experiment

\begin{tabular}{cccccc}
\hline Source & DF & SS & MS & $\boldsymbol{F}$-values & $\boldsymbol{p}$-values \\
\hline $\mathrm{X}_{1}$ & 1 & 8256179 & 8256179 & 171.26 & $<0.0001$ \\
$\mathrm{X}_{2}$ & 1 & 5632495 & 5632495 & 116.83 & $<0.0001$ \\
$\mathrm{X}_{3}$ & 1 & 1366909 & 1366909 & 28.35 & 0.0002 \\
$\mathrm{X}_{4}$ & 1 & 624593 & 624593 & 12.96 & 0.0037 \\
$\mathrm{X}_{1}^{2}$ & 1 & 4547926 & 4547926 & 94.33 & $<0.0001$ \\
$\mathrm{X}_{1} \mathrm{X}_{2}$ & 1 & 15901 & 15901 & 0.33 & 0.5764 \\
$\mathrm{X}_{1} \mathrm{X}_{3}$ & 1 & 349376 & 349376 & 7.25 & 0.0196 \\
$\mathrm{X}_{1} \mathrm{X}_{4}$ & 1 & 1025 & 1025 & 0.02 & 0.8865 \\
$\mathrm{X}_{2}^{2}$ & 1 & 7657371 & 7657371 & 158.83 & $<0.0001$ \\
$\mathrm{X}_{2} \mathrm{X}_{3}$ & 1 & 62263 & 62263 & 1.29 & 0.2780 \\
$\mathrm{X}_{2} \mathrm{X}_{4}$ & 1 & 2908 & 2908 & 0.06 & 0.8101 \\
$\mathrm{X}_{3}^{2}$ & 1 & 4839826 & 4839826 & 100.39 & $<0.0001$ \\
$\mathrm{X}_{3} \mathrm{X}_{4}$ & 1 & 360901 & 360901 & 7.49 & 0.01806 \\
$\mathrm{X}_{4}^{2}$ & 1 & 2729677 & 2729677 & 56.62 & $<0.0001$ \\
Model $_{\text {Lack of fit }}$ & 14 & 27185741 & 1941839 & 40.28 & $<0.0001$ \\
\hline & 566425 & 56642 & 9.37 & 0.1002 \\
\hline
\end{tabular}

Table 5 Analytical characteristics of the proposed method

\begin{tabular}{lll}
\hline Parameters & d-CPE method & CPE method \\
\hline Regression equation & $\mathrm{F}=979.28 \mathrm{C}(\mu \mathrm{g} / \mathrm{L})+211.96$ & $\mathrm{~F}=146.33 \mathrm{C}(\mu \mathrm{g} / \mathrm{L})-54.824$ \\
Regression coefficient $\left(\mathrm{r}^{2}\right)$ & 0.9980 & 0.9625 \\
Linear range $\left(\mu \mathrm{gL}^{-1}\right)$ & $0.5-6.0$ & $0.5-6.0$ \\
$\mathrm{LOD}\left(\mu \mathrm{gL}^{-1}\right)^{\mathrm{a}}$ & 0.023 & 0.141 \\
$\mathrm{RSD} \%(\mathrm{n}=10)$ & 4.04 & 12.6 \\
Enhancement factor $^{\mathrm{b}}$ & 11.8 & 1.77 \\
\hline
\end{tabular}

${ }^{\mathrm{a}}$ Limit of detection (LOD) is defined as the ratio of three times the standard deviation of 10 measurements of the blank signals and the slope of the calibration curve.

${ }^{\mathrm{b}}$ Enhancement factor (EF) is defined as the ratio of the slope of preconcentrated samples $(50 \mathrm{ml})$ to that obtained without preconcentration. 
Table 7 Determination of samples and recoveries $(n=3)$

\begin{tabular}{|c|c|c|c|}
\hline Sample & $\begin{array}{c}\operatorname{Se}(I V) \text { added } \\
(\mu \mathrm{g} / \mathrm{g})\end{array}$ & $\begin{array}{c}\mathrm{Se}(\mathrm{IV}) \\
\text { measured } \\
(\mu \mathrm{g} / \mathrm{g})\end{array}$ & $\begin{array}{c}\text { Recovery } \\
(\%)\end{array}$ \\
\hline \multirow{2}{*}{ Spirulina } & - & 0.0858 & - \\
\hline & 0.091 & 0.1731 & 96.0 \\
\hline \multirow{2}{*}{ Seaweed } & - & 0.0711 & - \\
\hline & 0.073 & 0.1440 & 100.3 \\
\hline \multirow{2}{*}{ Wakame } & - & 0.0992 & - \\
\hline & 0.100 & 0.1970 & 97.8 \\
\hline \multirow{2}{*}{ Laver } & - & 0.1820 & - \\
\hline & 0.180 & 0.3541 & 95.6 \\
\hline \multirow{2}{*}{ Tea leaf } & - & 0.0353 & - \\
\hline & 0.036 & 0.0716 & 100.0 \\
\hline \multirow{2}{*}{ Mushroom } & - & 0.0512 & - \\
\hline & 0.050 & 0.1102 & 97.1 \\
\hline \multirow{2}{*}{ Black fungus } & - & 0.0470 & - \\
\hline & 0.050 & 0.0996 & 105.2 \\
\hline \multirow{2}{*}{ Tremella } & - & 0.0786 & - \\
\hline & 0.078 & 0.1552 & 98.2 \\
\hline \multirow{2}{*}{ Rice } & - & 0.0493 & - \\
\hline & 0.050 & 0.1010 & 103.5 \\
\hline \multirow{2}{*}{ Wheat } & - & 0.0631 & - \\
\hline & 0.065 & 0.1271 & 98.5 \\
\hline \multirow{2}{*}{ Soya } & - & 0.0572 & - \\
\hline & 0.050 & 0.1083 & 102.2 \\
\hline \multirow{2}{*}{ corn } & - & 0.0356 & - \\
\hline & 0.040 & 0.0772 & 104.0 \\
\hline
\end{tabular}

